\title{
Krize Müdahale Merkezine Başvurularda Yaşam Olaylarının Değerlendirilmesi*
}

\author{
B.Ceyhun**, G. Ergin**, A.Duran**
}

Özet: Yaşam süreci içinde her birey hayatımın bir döneminde alışımamış olağandışı bir olayla veya durumla karşılaşabilir. Birey bu yeni duruma sağlıklı uyum yapamadığı zaman "kriz" olarak tanımlanabilen heyecansal bir yaşantı içine girebilir. Çalışmada kriz durumu içinde merkeze başvuran bireylerde elkin olan yaşam olayları araştırımıştır. Krize Müdahale Merkezine başvuran 90 denekte yaşam olayları belirienmiş ve intihar girişimi olan 90 denekto intihara neden olan yaşam olayları ilo karşilaştırıınışır. Araştırma bulgularına gờe başvuran grubun çoğunluğu genç ve kadındır. Yaşam olaylarında alle igi ilişki sorunlarında ve fiziksel cezalandırımada (ör. dayak) iki grup arasindaki fark anlamidir $(p<0.01)$.

Summary: In October 1989 the tirst "Crisis Intervention Center" in Turkey has been established. During the last year180 of the patients were seen in this center with suicide attempts and crisis. Most of the patients were women age range were between 14-50. This paper reviews evidence for a strong aetiological connection between life stress and development of a crisis and sulcide attempt. The results of the sample has shown that punishment is a significant variable in the development of suicidal attempts especially if it leads to a tong lerm disorganization in family life.

Bir kavram olarak yaşam olayları terimi kişinin yasamını anlamıl derecede etkileyen oiaylar için kulanilmaktadır(Kessler ve Price 1985).

Yaşam olaylarına ilişkin araştırmaları cơ̆u Cannon ve Selye'nin oncü çalışmalarına dayanmaktadır. Bu kuramcilara göre birsy yaşamının bir döneminde alışıłamamış, olağandışı bir olayla veya durumla karşılaşabilir. Birey yaşam olayları sonucunda ortaya cikan yeni duruma uyum yapamadığı zaman kriz durumu ortaya çıkabilir. Krizin tipik seyrinde Caplan(1964) 4 ayrı dönem tanimlamaktadir.

1. Birinci dönemde belirli ihtiyaçların karşılanmasını tehdit eden bir sorunla karşılaşan birey gerginliğine karşı duygusal dengesini yeniden kurmak için alışageldiŏgi sorun çōzme teknikleri kullanır.

2. İkinci dönem alışılagelen yöntemlerin başarısız olduğu, tehdidin sürdüğü gerginliğin daha da artarak yetersizlik duygularının ortaya çıktığı dönemdir. Birey sorunu çözmek için deneme yanilma yollarına başvurur.

3. Bu dönemde sorunu çözme konusunda başarısızlık sưrmektedir. Gergınlik artmıştır. Bu ise acil ve yeni problem çözme yoliarınin harekete geçirilmesi için bir uyaran oluşturur. Bütün iç ve diş kaynaklar harekete geçirilir. Bunun sonucunda birey bazen sorunu çŏzer. Ulaşıımaz görünen amaçların bir kısmından vazgeçilir ve birey kendinj soruna göre yeniden ayarlar.

4. Sorun devam ediyor çözülemiyor giderek artıyorsa dördūncũ aşamaya ulaşılır. Bu aşamada depresyon, gerginlik, intiharlar kendini gösterir.

Krizi önlemede krizi ortaya çikaran yaşam olaylarının belirlenmesi önemlidir. Bu amaçia yaşam olayları araştırmaları geniş boyutlarda ele alınmaktadır. Belirgin yaşam otaylarına or, yas,

* XXVII Ulusal Psikiyatri Kongresinde bildiri olarak sunulmuştur.

** Ankara Üniversitesi Psıkiyatrik Kriz Uygulama ve Araştırma Merkezi 
bedensel hastaiıklar... vs. ilişkin araştırmalarda olayların psikiyatrik hastalıklar ve inthardaki etkinliği üzerinde durulmaktadır. Birtchnell (1970) intihar girişimi olan bireylerle yaptığı çalışmada, intihar öncesi ebeveynlerden birinin ölümünūn bu grupta diğer psikiyatrik bozukluklardan daha yōksek olduğunu saptamıştır. Paykel ve ark. (1975) yaşam olayları ölçeğini geliştirmeyi amaçladıkları çalışmalarında intihar girışimi olan 53 deneği yaş ve cinsiyet açısından eşleştirdikleri depresif ve normal grupla karşılaştırmış, sosyal ilişkilerdeki güclüklerin intihar girişimli grupda daha fazla görüldüğünü saptamıştır. Yine aynı araştırmada intihar girişimi olan grubun normal gruptan dört depresyon grubundan ise birbuçuk kat daha fazla yaşam olayı bildirdikleri dikkat çekicidir. Paykel (1978)'ın yaptığı diğer bir çalışmada belirgin tehdit edici yaşam olaylarını takip eden 6 ay içinde depresyon gefiștirme riskinin altı kat, şizofreni geliştirme riskinin iki ila dört kat, intihar riskinin ise yedi kat daha fazla olduğunu bildirilmektedir.

Yapilan bu çalısmada amaç krize müdahale merkezine başvurularda kriz durumlarına neden olan yaşam olaylarını belirlemeye çalışmaktır. Krizin çözümienemediği ve intihar girişiminin son çare olarak görüldüğŭ durumlarda etkin olan yaşam olaylarının yoğunluğu, kriz durumu ile başvuran bireylerin yaşam ofayları ile karşılaştırılmıs ve girişim öncesi bireylere yardımda etkin olabllecek kriterler araştır:mış̧tı.

\section{YÖNTEM}

Denekler: Orneklem grubu, Haziran 1990-Haziran 1991 tarihleri arasında Kriz Merkezinde görülen 180 kişiden oluşmaktadır.

Kriz Grubu: Bu grup 1 yll içinde A.Ü. Psikiyatrik Kriz Uygulama ve Araştırma Merkezine kriz durumu ile gelen 90 kișiden oluşmaktadır. Grubun 72'si kadın, 18'i erkektir. Yaş ranjı 20-50 arasında değişmektedir. Deneklerin çoğunluğu evlidir.

Intihar Girisimi Grubu: A.Ü. Psikiyatrik Kriz Uygulama ve Araştırma Merkezine 1 yıl içinde intihar girişımi sonucunda görülen 90 kissidir. Grubun 78'i kadin, 12'si erkektir. Yas ranji 15-50 arasında değiş̧mektedir. Deneklerin çoğunluğu bekår ve öğrencidir.

Intihar girişimi için belirlenen kriterler şunlardır:

1.Olayın bireyin kendisi tarafından başlatıması.

2.Daha önceden planlanmıs olması.

3.Bireyin aldığı maddenin etkinliği hakkında bilgisinin olması.

Görüşme ve Işlem: Demografik verilerin belirlenmesi amaciyla her hasta için yarı yapılandırılmış görüşme tekniğ; kullanılmıştır. Yaşam olaylarının araştırımasında Paykellin (1975) geliştirdiği ve 61 yaşam olayını içeren liste kuillanilmıştır.

Kriz durumu ile gelen bireylere geldikleri gün Krize Müdahale Merkezinde görüşúlmúş ve daha sonraki görüşmeler planlanmıştır.

Intihar girişimi ile acil servise getirilen ve illş̧ kurulabilecek durumda olan bireylerle ilk görüșme acil serviste yapılmus ve daha sonra Krize Müdahale. Merkezinde izlenmişlerdir.

Paykel'in yaşam olayları için geliştiridiği yarı yapilandırılmış liste görüşme sırasında bireylerden alınan bilgilere dayanılarak doldurulmus her birey için görūşme sonrası yaşam olayları sıralaması yapılmıştır. Araştırma sırasında listede olan maddelerin bir kısmı hiç görülmediği veya çok az sayıda bireyde görüldūğú için Istedeki madde sayısı 16 ile sınırfandırılmıştır.

Yaşam olaylarının gruplar arası anlamlıh̆gı $X^{2}$ önemlilik testi ile değenlendirilmiştir.

\section{BULGULAR}

Bu çalısmada örneklem grubunun demografik ozzelikkleri Tablo l'de verilmiştir. Erkek deneklerin sayısı (Kriz grubunda 18, intihar girişimi grubunda 12) az olduğu için cinsiyet aynmı yapılmamıştır.

Tablo f'de görüldüğa gibi intihar girişimi grubu kriz grubundan daha gençtir. Intihar girişimi grubunun \%78'1 15-29 yaşłarı arasındadır. Kriz grubunun \%45'i aynı yaş ranjında yer almaktadır. Yaş dağıımı açısından bakıldığında 20 yaş ve altı grubunda gruplar arası fark anlamlidir $\left(X^{2}=\right.$ $14.55>X^{2} 0.001,1=10.82$ ).

Tablo Il'de intihar girişimlerinde kullanılan yöntemler verilmiş̧tir.

Yaşam olaylarının bildirim sayısı açısından bakıldığında 180 vakada 312 olay bildirimı olduğu gỏrülmektedir $\left({ }^{-} x\right.$ olay $\left.=1.73\right)$ İntihar girişimi grubunda 57 kişide $(\% 63)$ birden fazla olay bildirimi vardır. Kriz grubunda krize neden olan olay krizden önceki 1 aylik zaman dilirini Içinde, intihar girişimi grubunda ise 15 gün içinde yer almaktadır.

Tablo Ill'te yaşam olaylarının görülme sıklığ ve gruplararası anlamlılık düzeyleri verilmiş̧tir. Bazı yaşam olaylarının bildiriminde sayı çok düşük olduğu için istatistiksel işlem yapılamamıştır. 
TABLO I: Örneklemin Demografik Ōzejlikteri

\begin{tabular}{|c|c|c|c|c|}
\hline & $\begin{array}{c}\text { intihar Girişir } \\
\text { Grubu } \\
(N=90)\end{array}$ & & $\begin{array}{c}\text { Kriz } \\
\text { Grubu } \\
(N=90)\end{array}$ & \\
\hline \multicolumn{5}{|l|}{ VAS } \\
\hline $\begin{array}{l}19 \text { ve altt. } \\
20-29 \\
30-39 \\
40-49 \\
50-59\end{array}$ & $\begin{array}{c}33 \\
37 \\
17 \\
2 \\
1\end{array}$ & $\begin{array}{l}\% 36.6 \\
\% 41.1 \\
\% 18.8 \\
\% 2.2 \\
\% 1.1\end{array}$ & $\begin{array}{l}11 \\
29 \\
28 \\
12 \\
13\end{array}$ & $\begin{array}{r}\% 12.2 \\
\% 32.2 \\
\% 31.1 \\
\% 13.3 \\
\% 14.4 \\
\end{array}$ \\
\hline \multicolumn{5}{|l|}{ EĞiTiM } \\
\hline $\begin{array}{l}\text { lik } \\
\text { Orta } \\
\text { Lise } \\
\text { Yäksek }\end{array}$ & $\begin{array}{c}43 \\
25 \\
16 \\
6\end{array}$ & $\begin{array}{l}\% 47.7 \\
\% 27.7 \\
\% 17.7 \\
\% 6.6\end{array}$ & $\begin{array}{l}27 \\
24 \\
27 \\
12\end{array}$ & $\begin{array}{l}\% 30.0 \\
\% 26.6 \\
\% 30.0 \\
\% 13.3\end{array}$ \\
\hline \multicolumn{5}{|l|}{ MEDENI DURUM } \\
\hline $\begin{array}{l}\text { Bekár } \\
\text { Evli } \\
\text { Dul }\end{array}$ & $\begin{array}{c}48 \\
39 \\
3\end{array}$ & $\begin{array}{ll}\% & 53.3 \\
\% & 43.3 \\
\% & 13.3\end{array}$ & $\begin{array}{r}26 \\
60 \\
4\end{array}$ & 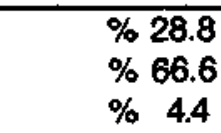 \\
\hline \multicolumn{5}{|l|}{$\begin{array}{l}\text { SOSYO EKONOMIK } \\
\text { DURUM }\end{array}$} \\
\hline $\begin{array}{l}\text { Alt } \\
\text { Orta } \\
\text { Yóksek }\end{array}$ & $\begin{array}{r}6 \\
52 \\
4\end{array}$ & $\begin{array}{l}\% 6.6 \\
\% 57.7 \\
\% 4.4\end{array}$ & $\begin{array}{l}17 \\
56 \\
17\end{array}$ & $\begin{array}{ll}\% & 18.8 \\
\% & 62.2 \\
\% & 18.8\end{array}$ \\
\hline \multicolumn{5}{|l|}{ MESLEK } \\
\hline $\begin{array}{l}\text { Ev hanımı } \\
\text { Memur } \\
\text { Ögrenci } \\
\text { Serbest }\end{array}$ & $\begin{array}{c}40 \\
13 \\
22 \\
5\end{array}$ & $\begin{array}{ll}\% & 44.4 \\
\% & 14.4 \\
\% & 24.4 \\
\% & 5.5\end{array}$ & $\begin{array}{c}30 \\
33 \\
14 \\
5\end{array}$ & $\begin{array}{ll}\% & 33.3 \\
\% & 36.6 \\
\% & 15.5 \\
\% & 5.5\end{array}$ \\
\hline
\end{tabular}

Yaşam olayları açısından değerlendirildiğinde kriz ve intihar girişimi grubunda dayak konusunda
$\left(X^{2}=12.76>X^{2} \quad 0.001,1=10.82\right)$ gözlenen ve beklenen frekanslar arasındaki fark istatistiksel

TABLO II: Intihar Girlşımlerinde Kullantlan Yöntemler.

\begin{tabular}{|l|c|c}
\hline Intihar Yöntemi & $\begin{array}{l}\text { Kadın } \\
(\mathrm{N}=78)\end{array}$ & $\begin{array}{l}\text { Erkek } \\
(\mathrm{N}=12)\end{array}$ \\
\hline llaç & 78 & 9 \\
Kesi & - & 2 \\
Atlama & - & 1 \\
\hline
\end{tabular}


$(X 2=5.72>X 20.05,1=3.84)$ iki grup arasindaki fark istatistiksel olarak önemlidir. Arkadaş ile iliş̧ki sorunlarına dayanan yaşam olaylarında intihar girişimi ve kriz grubunda görülme sıklığ eşittir.

\section{TARTIŞMA}

Araştırmada intihar girişimi grubu kriz grubundan daha gençtir ve aile içi iliş̧i sorunları ve dayağın kullaniıması dikkat çokicidir. Ailenin ergenden beklentileri, arkadas grubu ile olan anlşmaziıklar, ergene katı bir disiplin uygulama isteği, çatışmaları doğurmaktadır (Palabıyıkoğlu, 1989). Aile ile ergen aynı yoğunluktadır. Yalnız intihar giriş̧imi grubunda kocanın karısın dővmesi kriz grubundan anlamlı düzeyde yüksektir. Kadınlarda eş ile ilişki sorunlarının yanısıra dayağın bir ceza olarak kullanıııması bardağı taşıran son damla olmakta ve kadın ancak intihar girişimde bulunarak bu durumdan kurtulmaya çalışmaktadır. Kadıniarın eşleri tarafından dayak ile cezalandırıldıkları kriz durumunda başvuracakiarı bir merkezin olması ónemlidir. Bu amaçla istanbul'da 1991 yilinda yataklı, Ankara'da ise telefon ve bizzat başvurulan iki kadin sı̆̆ınma evinin açıımış olmasının kadınlara yardım sağiayacağını ve intharı azaltabileceğini ümit etmekteyiz. Hern kriz hem de inthar girişimi iģin

TABLO III: Yaşam Olaylarının Görülme Sıklığı

\begin{tabular}{|c|c|c|c|}
\hline Yasam Olayı & Int. Gir. & Kriz & Int. Gr. AKiz \\
\hline $\begin{array}{l}\text { 1. Dayak } \\
\text { 2. Aile ile ilgili sorun } \\
\text { 3. Eş ile ilgili sorun } \\
\text { 4. Arkadaş ile ilgili sorun } \\
\text { 5. Okul sorunu } \\
\text { 6. Ciddi maddi soruntar } \\
\text { 7. Evlenme } \\
\text { 8. Ciddi organik hastalık } \\
\text { 9. Aile üyelerinden birinde ciddi hastalık } \\
\text { 10. Aile üyelerinden birinin ölümü } \\
\text { 11. Işte başarısızlık } \\
\text { 12. Işsizlik } \\
\text { 13. Boşanma } \\
\text { 14. Çocuğun evlenmesi } \\
\text { 15. Taşınma/şehir değiştirme }\end{array}$ & $\begin{array}{r}20 \\
30 \\
33 \\
35 \\
10 \\
9 \\
8 \\
6 \\
- \\
1 \\
1 \\
- \\
- \\
2 \\
1\end{array}$ & $\begin{array}{r}3 \\
16 \\
36 \\
35 \\
5 \\
11 \\
3 \\
15 \\
5 \\
7 \\
6 \\
2 \\
4 \\
1 \\
2\end{array}$ & $\begin{array}{r}<.001 \\
<.05 \\
7\end{array}$ \\
\hline
\end{tabular}

arasındaki çatışma ergeni intihara kadar götürebilir. 1971 yilında Sonuvar ve Yörükoğlu'nun 30 çocuk ve gençten oluşan bir grup ile yaptıkları çalışmada intihara neden olan olaylar içinde ilk sirayl azar ve dövme (\%56), ikinci sirayı isteklerin yapılmamasi ve erkek - kız ilişkisi (\%6.6) almıştır. Yaklaşık 20 yıl sonra yapılan bu çalışmada dayağın hålâ intihara yol açan önemli bir neden olması ilginçtir. Palabıyıkoğlu ve Canat'ın (1987) A.U.T.F. Psikiyatri Kliniği ergen birimine intihar girişimi ile başvuran gençerle yaptıklari çalışmada ana-baba ile tartışma, karşı cinsten arkadaşı ile ilişkide bozulma ve akademik başarısızlık sonucu bu davranışa başvurdukkarı saptanmıştır. Araştırmada cinsiyet açısından kadınların yoğunluğu dikkat çekicidir. Kriz ve inthar girişimi grubunda eş ile ilgili sorunlar ortaya çıkartcı faktör olarak kabul edilebilecek olayların alle ile ilglil yaşam alanlarında birikmesi, aile He tedavi sürecinde iş̧birliğinin sağlanmasının önemini bir kez daha gündeme getirmektedir. Terapistin ana baba, tüm alle lle beraber konuşması uygun tedavi yaklaşımı için gereklidir. Alle içi güçlükleri cözmede iletişimin arttırımasına önem verilmesi íleride ortaya cıkabilecek kriz durumlarını ônleme açısından da yararlı olabilir. 
KAYNAKLAR

Birtchnell, J. (1970) The relationship between aftempted suicide, depression and parent death. British Joumal of Psychiatry, 116, 303-313.

Canat, S.: Palabıyıkoğlu, $R$ (1987) Ergenierin MMPI profil örüntoleri. $X X I I I$. Ulusal Psikiyatri ve Nörolojik Bilimier Kongresi 14-18 Eylül 1987, istanbul.

Caplan, G (1964) Principles of Preventive Psychiatry. New York: Basic Books.

Kessler, R.C. (1979) Siress, social slatus and psychological distress. Journal of Health and social Behavior, 20, 259-272.

Kessler, A.C.: Price, R.H.: Wortman, C.B. (1985) Social factors in psychopathology: Stress, social support and coping processes. Annual Review of Psychology. 36, p: 531-572.
Palabıyıkoğlu, $R$ (1989) Ergenlik Çağı Krizjeri Yaklaşım ve Konuyucu Programiar, Psikiyatride Krize Müdahale Çalişma Grubu. XXV Utusal Psikiyatri ve Nörolojik Bilimler Kongresi 15-21 Ekim, t989, Mersin.

Paykel, E.S., et al. (1975) Scaling of life events. Archieves of General Psychiatry .25, 340-363.

Paykel, E.S. (1978) Contribution of life events to causation of psychiatric illness. Psychological Medicine. 8, 245-253.

Sonuvar, B.: Yörükoglu, A (1971) Çocukluk ve delikanlilı gağında intihar girişimleri. Hacettepe Tip/Cerrahi Bölteni. 4(2), 136-150. 